\title{
Inflammatory bowel disease clinical service recovery during the COVID-19 pandemic
}

\author{
Shahida Din (1) , ${ }^{1}$ Daniel Gaya, ${ }^{2}$ Jochen Kammermeier (1) ${ }^{3}$ Christopher A Lamb (D) ,,5 \\ Jonathan Macdonald, ${ }^{6}$ Gordon Moran, ${ }^{7,8}$ Gareth Parkes, ${ }^{9}$ Richard Pollok, ${ }^{10}$ \\ Shaji Sebastian (D) , ${ }^{11}$ Jonathan Segal (D) , ${ }^{12}$ Christian Selinger, ${ }^{13}$ Philip J Smith (D) , ${ }^{14}$ \\ Helen Steed, ${ }^{15}$ Ian D Arnott ${ }^{16}$
}

\begin{abstract}
${ }^{1}$ Edinburgh IBD Unit, Western General Hospital, Edinburgh, UK, ${ }^{2}$ Gastroenterology Unit, Glasgow Royal Infirmary, Glasgow, UK, ${ }^{3}$ Pediatric Gastroenterology, Evelina London Children's Hospital, London, UK, ${ }^{4}$ Institute of Cellular Medicine, Newcastle University, Newcastle Upon Tyne, UK, ${ }^{5}$ Department of Gastroenterology, Newcastle Upon Tyne Hospitals NHS Foundation Trust, Newcastle Upon Tyne, UK, ${ }^{6}$ Department of Gastroenterology, Queen Elizabeth University Hospital, NHS Greater Glasgow and Clyde, Glasgow, UK, ${ }^{7} \mathrm{NIHR}$ Nottingham Biomedical Research Centre, Nottingham University Hospitals NHS Trust, Nottingham, UK, ${ }^{8}$ Nottingham Digestive Diseases Centre, University of Nottingham, Nottingham, UK, ${ }^{9}$ Department of Gastroenterology, Royal London Hospital, London, UK, ${ }^{10}$ Gastroenterology, St George's Hospital, London, UK, ${ }^{11}$ IBD Unit, Hull University Teaching Hospitals NHS Trust, Hull, UK, ${ }^{12}$ Department of Gastroenterology, The Hillingdon Hospitals NHS Foundation Trust, Uxbridge, UK, ${ }^{13}$ Leeds Gastroenterology Institute, St James's University Hospital, Leeds, UK, ${ }^{14}$ Department of Hepatology and Liver Transplantation, Royal Liverpool and Broadgreen Hospitals NHS Trust, Liverpool, UK, ${ }^{15}$ Department of Gastroenterology, New Cross Hospital, Wolverhampton, UK, ${ }^{16}$ The Edinburgh IBD Unit, Western General Hospital, Edinburgh, UK
\end{abstract}

The COVID-19 pandemic disrupted healthcare services across the world with only essential care being continued. ${ }^{12}$ For paediatric and adult patients with inflammatory bowel disease (IBD), this resulted in significant changes to accessing health services. In some services, IBD advice lines were stopped, specialist nurses and medical staff were redeployed to support acute admissions, outpatient clinics were deferred, and home care services were under threat. ${ }^{34}$ In addition, there was a reluctance from patients to come to hospital or contact their services due to concerns over their personal safety. ${ }^{56}$

The Crohn's and Colitis United Kingdom (CCUK) 'life in lockdown' patient survey reported that patients felt their IBD teams kept them well informed of coronavirus and their condition. Importantly, one in five patients reported that they also received inaccurate information on other aspects such as shielding. ${ }^{7}$

The pandemic has also highlighted the disparities in accessing healthcare ${ }^{8}$ and addressing these alongside organisational transformation will support personalised care, which is one of the main recommendations of the Inflammatory Bowel Disease United Kingdom (IBD UK) standards. ${ }^{9}$

Healthcare services have restarted routine clinical practices responding swiftly to regional and national lockdowns in the second wave. ${ }^{10}$ Additionally, local data have allowed clinical teams to refine service delivery supporting those most vulnerable to poorer outcomes if they develop COVID-19. ${ }^{11} 12$
The British Society of Gastroenterology (BSG) has commissioned independent reviews on the redesign of outpatient services focusing on telemedicine and restarting endoscopy safely. ${ }^{13-20}$ The COVID-19 pandemic effect on clinical research and trial activity are being addressed separately by the BSG IBD research committee. ${ }^{121}$

We are currently in our second wave of the pandemic and a third national lockdown with increasing pressure to maintain specialist services as well as directly supporting care for patients with COVID-19. We have, therefore, considered the additional key aspects of maintaining a functional IBD service, ${ }^{9}$ which is resilient, adaptable and can adjust efficiently to regional variations and future pandemics.

\section{MAINTAINING A FUNCTIONAL IBD TEAM}

We have a responsibility to maintain scheduled care and it is essential that the team is preserved to lead the IBD service during future pandemics (figure 1). The BSG and European Society of Paediatric Gastroenterology, Hepatology and Nutrition (ESPGHAN) IBD guidelines and the IBDUK standards have described the components of a functional multidisciplinary IBD team. ${ }^{92-25}$ In addition to senior clinical decision-makers, specialist IBD nurses, endoscopy teams, dieticians, pharmacists and mental health services are all crucial aspects that will help keep patients in remission. For example, rapid access for inpatients and outpatients to exclusive enteral nutrition as an alternative to steroid therapy in adult patients with 


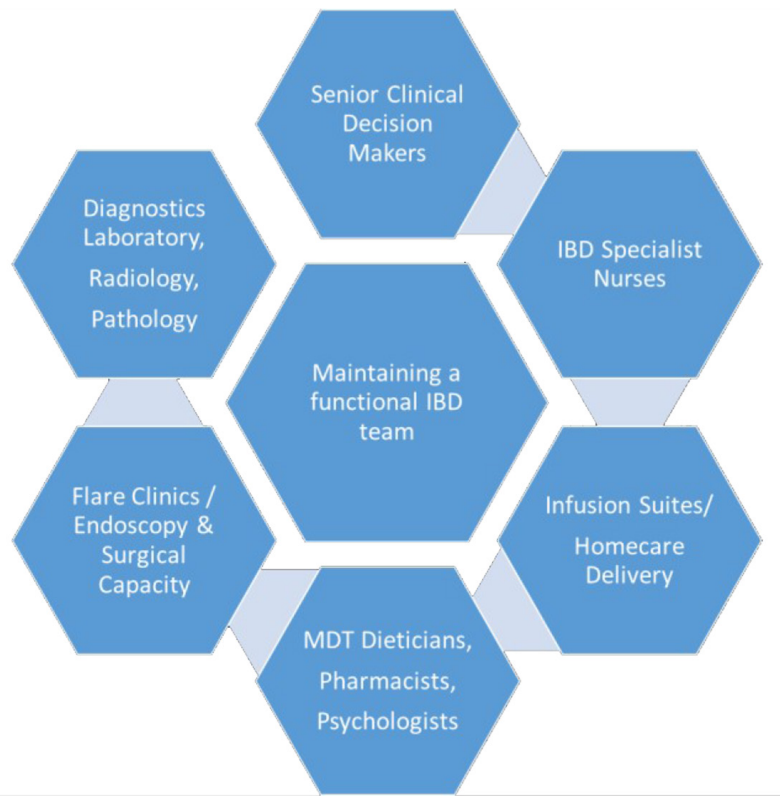

Figure 1 The components of an essential multidisciplinary IBD team. IBD, inflammatory bowel disease. MDT, multidisciplinary teams.

Crohn's disease will mitigate any additional treatmentrelated adverse outcome.

\section{PATIENT SUPPORT}

The uncertainty of the COVID-19 pandemic has caused significant physical, emotional and psychological stress for patients. ${ }^{5}$ 26-28 The key concerns for patients are delays to diagnosis and planned procedures/surgery, accessible relevant information, securing the continued support of specialist IBD teams and maintenance of drug treatment. ${ }^{29}$ Improved coordination between central government, the National Health Service (NHS), specialist clinicians, community primary care teams and patient charities is needed to minimise patients receiving inaccurate or conflicting information. Patient charities provide a reliable source of accessible information and support to patients during and beyond the pandemic.

\section{NEW DIAGNOSIS OF IBD}

The BSG IBD Committee would support a National diagnostic pathway for referral of suspected IBD with specified and mandated waiting time threshold(s) as outlined in the IBDUK standards. The time to diagnosis of IBD has been a major concern prior to the COVID-19 pandemic. Only 38\% of services surveyed in the IBDUK Benchmarking audit had the ability to review patients within 4 weeks of a suspected referral for IBD. ${ }^{9}$ Access to diagnostic endoscopy and radiology contribute to this delay ${ }^{30}$ and are likely to be accentuated due to the continuing pressure to maintain physical distancing. ${ }^{31}$ The BSG endoscopy executive committee recommends high-level triage by senior decisionmakers and use of adjuncts such as faecal calprotectin and/or quantitative faecal immunochemical test to help identify patients for urgent endoscopic investigations. For IBD specifically, we would recommend prioritising endoscopy resources for patients with a suspected diagnosis of IBD, disease assessment to guide decision-making and annual colorectal surveillance. ${ }^{32}$ The empirical treatment of patients with possible IBD can confound and potentially delay a definitive diagnosis and can delay the start of effective maintenance treatment. We strongly support the use of noninvasive tests, such as faecal calprotectin, to identify those who should be prioritised for urgent investigation, allowing the best use of available resources. IBD teams should work collaboratively with primary care providers to develop pathways to ensure the rapid diagnosis and treatment of people with IBD. This will, allow timely effective treatment, prevent unnecessary investigation and may prevent hospital admission.

\section{FAECAL CALPROTECTIN}

The BSG guidelines ${ }^{22}$ and National Institute for Health and Care Excellence (NICE) (Diagnostic Guidance 11) both advocate the use of faecal calprotectin as a tool to help identify patients for more urgent investigations when IBD is suspected. A faecal calprotectin level of $100-250 \mu \mathrm{g} / \mathrm{g}$ has a $12 \%$ likelihood of reflecting IBD and a faecal calprotectin $>250 \mu \mathrm{g} / \mathrm{g}$ has a $46 \%$ likelihood of identifying IBD accurately. ${ }^{33}$ Faecal calprotectin services were disrupted during the COVID-19 pandemic with two-thirds of UK services reporting a reduction or suspension of this critical service. ${ }^{3}$ There are several ways a faecal calprotectin test can be undertaken within these restrictions including outsourcing if necessary to centralised services.

Conventional laboratory-based tests are ELISA based and can be achieved by posting completed forms and sample pots to patients and asking for these to be dropped off at the primary care surgery, if possible. The majority of primary care centres will have regular deliveries of samples to the central laboratories. This will involve a logistical challenge for the primary care team and many of whom are prearranging patient visits and have to personally accept samples from patients.

An alternative approach is to ask patents to postsamples directly to the central laboratories, which is routinely undertaken for clinical research and trials. This method will necessitate a clinical risk assessment to account for any faecal samples, which may leak in transit.

Point of care (POC) faecal calprotectin tests have been used more frequently during the pandemic. ${ }^{34}$ NICE (Medtech innovation briefing MIB132) has produced a useful comparison of POC and home faecal calprotectin tests for monitoring IBD against conventional laboratory testing. In addition to this, it is recommended to use the same manufacturer of the POC test and the companion ELISA. ${ }^{35}$ There are a few critical issues to consider when adopting POC home kits including patient education and learning, 
smartphone compatibility, number of tests per kit and a reliable system to review the POC results within your service. POC tests may be suitable for patients living in a remote geographical area or those who wish to minimise contact with healthcare facilities. ${ }^{36}$

\section{ESTABLISHED PATIENT WITH IBD}

The adoption of telemedicine including telephone and video clinics and IBD self-care applications has been welcomed by the majority of patients. ${ }^{13} 37$ A cohort of patients may not be suitable for telephone clinics or potentially find them challenging, for example, elderly, patients with learning disabilities, those requiring translation services or communication aids and those with perianal disease. Primary care teams have adopted a telephone triage system calling all patients and arranging face-to-face reviews if necessary. This could also work well for most patients in secondary care and offering face-to-face clinics for flaring patients is an acceptable model of care. In order to maintain clinical remission, it is imperative that IBD advice lines, infusion suites, homecare services and blood monitoring continue to be delivered reliably.

\section{IBD ADVICE LINES}

The ability for patients to contact their IBD service, especially without coming to hospital is critical during the pandemic. IBD advice lines recorded a 100\%$200 \%$ increase in calls throughout the peak of the pandemic and yet many reported that IBD teams and specifically nurse specialists were redeployed to help meet pandemic-related clinical service needs. ${ }^{3}$ Securing the role of the IBD nurses remains a priority especially if teams are considering a patient email service where advice can be sought and managed more efficiently. Patient email communication can also help to share rapid changes to clinical services in a timely manner. ${ }^{38}$

In adult patients, drug choice during the pandemic has shifted to more oral therapies such as elemental nutrition, tofacitinib or subcutaneous therapies such as golimumab, adalimumab and ustekinumab. ${ }^{38}$ Drug counselling is a key part of this process and a range of options are needed minimising hospital attendance. These may include telephone and video appointments delivered by IBD nurses and pharmacists with supporting written (CCUK website) or video resources (eg, https://vimeo.com/321246669). All patients attending scheduled activity should be prescreened for symptoms of cough, fever and loss of taste and smell. The physical plan of the infusion area should be arranged to support physical distancing and local infection control measures. ${ }^{39}$ Where possible, therapy should be de-escalated (if appropriate) and subcutaneous versions of biological therapies considered for the most vulnerable patients. ${ }^{40}$ For adult patients, subcutaneous infliximab and vedolizumab are available and consideration should be given to prioritise patients who would benefit from this therapy including new starts, comorbidity, poor venous access, long travelling distance and other responsibilities, which make it challenging to attend the hospital for regular infusions. ${ }^{41}$ Given the overall encouraging data and favourable outcomes in patients with paediatric IBD with COVID-19, the main emphasis in children has been to continue IBD management as per latest guidance to prevent disease relapse. ${ }^{42}$

\section{BLOOD MONITORING}

Therapeutic drug monitoring for immunomodulators and biological therapies should be actively undertaken to ensure patient safety and optimisation of medication to minimise disease flares. Regular monitoring should be aligned with infusion appointments and community phlebotomy clinics could be arranged at nonhospital healthcare sites. Data should be collected prospectively to assess the safety of adopting less frequent blood monitoring.

\section{COMMUNITY-BASED SERVICES}

Some IBD services have started to use communitybased IBD nurses to reduce health miles and bring highquality care closer to home. During the pandemic, the rational for such services is even greater and the use of cold sites should be supported.

\section{FLARING PATIENT WITH IBD}

Emerging evidence suggests that active IBD together with oral corticosteroids are associated with adverse outcomes in adult patients with IBD who contract COVID-19. ${ }^{11}$ It is, therefore, essential that a service is able to start treatment in a timely manner. For patients with IBD delays to treatment and diagnosis or planned surgery leads to a rise in emergency surgery, more extensive surgery, and life threatening complications, increased risks of cancer, mortality and disease progression.

Flare clinics should be delivered by senior clinical decision-makers with IBD nurse specialists, pharmacists and dieticians encompassing the steps necessary to start new biological treatment with counselling, screening and teaching of injection technique. Acute drug prescriptions providing patients with a minimum of 4 weeks therapy should be provided and homecare delivery arranged for maintenance therapy. Regular review of flaring patients is necessary to ensure that they have responded to the change in treatment.

The management of patients requiring inpatient treatment for ulcerative colitis has been addressed with a RAND/UCLA (University of California, Los Angeles) panel, ${ }^{43}{ }^{44}$ which has suggested several adaptations to the acute severe ulcerative colitis protocol in the BSG and ECCO/ESPGHAN IBD guidelines. ${ }^{22} 25$ The management of patients requiring an admission with Crohn's disease is often complicated and should be undertaken with involvement of the multidisciplinary team (MDT) including IBD specialists, IBD specialist 
nurses, dieticians, specialist nutritional team, surgeons and psychologists (where appropriate).

\section{CONCLUSION}

The risk of patients with IBD acquiring SARS-CoV-2 and developing COVID-19 will depend on their inherent personal risk factors and modifiable factors such as active IBD and immunosuppression. Fortunately, we will be able to refine the risk profile for each individual patient iteratively as more data become available. ${ }^{45}$ We recommend that effective treatment for IBD should not be postponed idefinately until patients have received the COVID-19 vaccine Three SARS-CoV-2 vaccines have been approved and the BSG and other organisations are in favour of patients with IBD to accept the first vaccine offered. ${ }^{47} 48$

Healthcare services and patients have rapidly adjusted to new working practices stimulated by the COVID-19 pandemic. Our next challenge is to truly transform our services using data-driven clinical decision-making, proactively monitoring disease and supporting patient engagement as the pandemic evolves.

Twitter Shahida Din@ShahidaDin1 and Philip J Smith@ DrPhilipJSmith

Acknowledgements We are grateful to Crohn's and Colitis UK for their review of the work.

Contributors SD and IDA planned and wrote the final version of the manuscript. SD, DG, CAL, JM, GM, GP, RP, SS, JS, CS, PJS, HS and IDA drafted and reviewed the manuscript. $\mathrm{JK}$ reviewed the manuscript and provided paediatric specific modifications to the manuscript.

Funding The authors have not declared a specific grant for this research from any funding agency in the public, commercial or not-for-profit sectors.

Competing interests None declared.

Patient consent for publication Not required.

Provenance and peer review Not commissioned; externally peer reviewed.

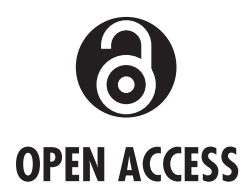

Open access This is an open access article distributed in accordance with the Creative Commons Attribution Non Commercial (CC BY-NC 4.0) license, which permits others to distribute, remix, adapt, build upon this work noncommercially, and license their derivative works on different terms, provided the original work is properly cited, appropriate credit is given, any changes made indicated, and the use is noncommercial. See: http://creativecommons.org/licenses/by-nc/4. $0 /$.

Correspondence to Dr Shahida Din, Edinburgh IBD Unit, Western General Hospital, Edinburgh EH4 2XU, UK; sdin@ed.ac.uk

Accepted 26 March 2021

Published Online First 21 April 2021

\section{A) Check for updates}

To cite Din S, Gaya D, Kammermeier J, et al. Frontline Gastroenterology 2022:13:77-81.
ORCID iDs

Shahida Din http://orcid.org/0000-0003-2855-3400

Jochen Kammermeier http://orcid.org/0000-0002-6046-8727

Christopher A Lamb http://orcid.org/0000-0002-7271-4956

Shaji Sebastian http://orcid.org/0000-0002-3670-6545

Jonathan Segal http://orcid.org/0000-0002-9668-0316

Philip J Smith http://orcid.org/0000-0003-1568-3978

\section{REFERENCES}

1 Kennedy NA, Jones G-R, Lamb CA, et al. British Society of gastroenterology guidance for management of inflammatory bowel disease during the COVID-19 pandemic. Gut 2020;69:984-90.

2 Danese S, Cecconi M, Spinelli A. Management of IBD during the COVID-19 outbreak: resetting clinical priorities. Nat Rev Gastroenterol Hepatol 2020;17:253-5.

3 Kennedy NA, Hansen R, Younge L, et al. Organisational changes and challenges for inflammatory bowel disease services in the UK during the COVID-19 pandemic. Frontline Gastroenterol 2020;11:343-50.

4 Danese S, Ran ZH, Repici A, et al. Gastroenterology department operational reorganisation at the time of covid-19 outbreak: an Italian and Chinese experience. Gut 2020;69:981-3.

5 D'Amico F, Rahier J-F, Leone S, et al. Views of patients with inflammatory bowel disease on the COVID-19 pandemic: a global survey. Lancet Gastroenterol Hepatol 2020;5:631-2.

6 Armellini E, Repici A, Alvisi C, et al. Analysis of patients attitude to undergo urgent endoscopic procedures during COVID-19 outbreak in Italy. Dig Liver Dis 2020;52:695-9.

7 CCUK. Life in Lockdown: what patients told us about their healthcare, 2020. Available: https://www.crohnsandcolitis.org. uk/healthcare-pro

8 Berkowitz SA, Cené CW, Chatterjee A. Covid-19 and Health Equity - Time to Think Big. N Engl J Med 2020;383:e76.

9 Kapasi R, Glatter J, Lamb CA, et al. Consensus standards of healthcare for adults and children with inflammatory bowel disease in the UK. Frontline Gastroenterol 2020;11:178-87.

10 Wise J. Covid-19: risk of second wave is very real, say researchers. BMJ 2020:m2294.

11 SECURE-IBD. SECURE-IBD registry: surveillance epidemiology of coronavirus (COVID-19) under research exclusion, 2020. Available: https://covidibd.org/updates-anddata/

12 Williamson E, Walker AJ, et al, The OpenSAFELY Collaborative. OpenSAFELY: factors associated with COVID19-related Hospital death in the linked electronic health records of 17 million adult NHS patients. medRxiv2020.

13 Douds A, Ransford R, Tham T. Bsg guidance: Rebooting gastroenterology and hepatology outpatients in the wake of COVID-19, 2020. Available: https://www.bsg.org.uk/covid-19advice/bsg-guidanc

14 Edwards C, Penman ID, Coleman M. Gastrointestinal endoscopy during COVID-19: when less is more. Frontline Gastroenterol 2020;11:256-7.

15 Rees CJ, East JE, Oppong K, et al. Restarting gastrointestinal endoscopy in the deceleration and early recovery phases of COVID-19 pandemic: guidance from the British Society of gastroenterology. Clin Med 2020;20:352-8.

16 Ravindran S, Matharoo M, Coleman M, et al. Teamworking in endoscopy: a human factors toolkit for the COVID-19 era. Endoscopy 2020;52:879-83.

17 Hayee Bu'Hussain, Thoufeeq M, Rees CJ, et al. Safely restarting Gi endoscopy in the era of COVID-19. Gut 2020;69:2063-70.

18 Penman I, Edwards C, Coleman M. Endoscopy activity and COVID-19: Bsg and JAG guidance. Br Soc Gastroenterol2020.

19 Catlow J, Beaton D, Beintaris I, et al. JAG/BSG national survey of UK endoscopy services: impact of the COVID-19 pandemic 
and early restoration of endoscopy services. Frontline Gastroenterol 2021;12:272-8.

20 Hayee B, East JE, et al, group TS project. A multi-centre prospective study of COVID-19 transmission following outpatient gastrointestinal endoscopy in the United Kingdom. medRxiv 2020.

21 Noor NM, Hart AL, Irving PM, et al. Clinical trials (and tribulations): the immediate effects of COVID-19 on IBD clinical research activity in the United Kingdom. J Crohns Colitis 2020. doi:10.1093/ecco-jcc/jjaa137. [Epub ahead of print: 29 Jun 2020].

22 Lamb CA, Kennedy NA, Raine T, et al. British Society of gastroenterology consensus guidelines on the management of inflammatory bowel disease in adults. Gut 2019;68:s1-106.

23 van Rheenen PF, Aloi M, Assa A, et al. The medical management of paediatric Crohn's disease: an ECCOESPGHAN guideline update. J Crohns Colitis 2020:jjaa161.

24 Turner D, Ruemmele FM, Orlanski-Meyer E, et al. Management of Paediatric Ulcerative Colitis, Part 1: Ambulatory Care-An Evidence-based Guideline From European Crohn's and Colitis Organization and European Society of Paediatric Gastroenterology, Hepatology and Nutrition. J Pediatr Gastroenterol Nutr 2018;67:257-91.

25 Turner D, Ruemmele FM, Orlanski-Meyer E, et al. Management of Paediatric Ulcerative Colitis, Part 2: Acute Severe Colitis-An Evidence-based Consensus Guideline From the European Crohn's and Colitis Organization and the European Society of Paediatric Gastroenterology, Hepatology and Nutrition. J Pediatr Gastroenterol Nutr 2018;67:292310.

26 Grunert PC, Reuken PA, Stallhofer J. Inflammatory Bowel Disease in the COVID-19 Pandemic: the Patients' Perspective. J Crohn's Colitis 2020:jjaa126.

27 Mir N, Cheesbrough J, Troth T, et al. COVID-19-related health anxieties and impact of specific interventions in patients with inflammatory bowel disease in the UK. Frontline Gastroenterol 2021;12:200-6.

28 Dorfman L, Nassar R, Binjamin Ohana D, et al. Pediatric inflammatory bowel disease and the effect of COVID-19 pandemic on treatment adherence and patients' behavior. Pediatr Res 2021. doi:10.1038/s41390-020-01312-6. [Epub ahead of print: 14 Jan 2021].

29 Harris RJ, Downey L, Smith TR, et al. Life in lockdown: experiences of patients with IBD during COVID-19. BMJ Open Gastroenterol 2020;7:e00541.

30 Blackwell J, Saxena S, Jayasooriya N, et al. Prevalence and duration of gastrointestinal symptoms before diagnosis of inflammatory bowel disease and predictors of timely specialist review: a population-based study. J Crohns Colitis 2020. doi:10.1093/ecco-jcc/jjaa146. [Epub ahead of print: $15 \mathrm{Jul}$ 2020].

31 Ashton JJ, Kammermeier J, Spray C, et al. Impact of COVID-19 on diagnosis and management of paediatric inflammatory bowel disease during lockdown: a UK nationwide study. Arch Dis Child 2020;105:1186-91.

32 Hayee B, East JE, et al, group TS project. A multi-centre prospective study of COVID-19 transmission following outpatient gastrointestinal endoscopy in the United Kingdom 2020.

33 Turvill J, Turnock D. Audit of the impact of the York faecal calprotectin care pathway on colonoscopy activity. Frontline Gastroenterol 2020;11:285-9.
34 Lees CW, Regueiro M, Mahadevan U, et al. Innovation in inflammatory bowel disease care during the COVID-19 pandemic: results of a global telemedicine survey by the International organization for the study of inflammatory bowel disease. Gastroenterology 2020;159:805-8.

35 Haisma S-M, Galaurchi A, Almahwzi S, et al. Head-To-Head comparison of three stool calprotectin tests for home use. PLoS One 2019; 14:e214751.

36 Shields S, Dunlop A, Seenan JP, et al. Disease monitoring of biologic treatment in IBD: early impact and future implications of COVID-19 pandemic. Frontline Gastroenterol 2021;12:345-7.

37 Tham TC, Douds AC, Ransford R. Challenges and opportunities of COVID-19 for gastroenterology and hepatology services. Frontline Gastroenterol 2021;12:342-4.

38 Sharma E, Meade S, D'Errico F, et al. The effects of COVID-19 on IBD prescribing and service provision in a UK tertiary centre. GastroHep 2020;2:318-26.

39 Clough JN, Hill KL, Duff A, et al. Managing an IBD infusion unit during the COVID-19 pandemic: service modifications and the patient perspective. Inflamm Bowel Dis 2020;26:e125-6.

40 Ben-Horin S, Leszczyszyn J, Dudkowiak R, et al. OP24 A novel subcutaneous infliximab (CT-P13): 1-year results including switching results from intravenous infliximab (CT-P13) in patients with active Crohn's disease and ulcerative colitis. J Crohn's Colitis 2020;14:S021-2.

41 Verma AM, Patel A, Subramanian S, et al. From intravenous to subcutaneous infliximab in patients with inflammatory bowel disease: a pandemic-driven initiative. Lancet Gastroenterol Hepatol 2021;6:88-9.

42 Turner D, Huang Y, Martín-de-Carpi J, et al. Corona virus disease 2019 and paediatric inflammatory bowel diseases: global experience and provisional guidance (March 2020) from the paediatric IBD Porto group of European Society of paediatric gastroenterology, hepatology, and nutrition. J Pediatr Gastroenterol Nutr 2020;70:727-33.

43 Din S, Kent A, Pollok RC, et al. Adaptations to the British Society of gastroenterology guidelines on the management of acute severe Uc in the context of the COVID-19 pandemic: a Rand appropriateness panel. Gut 2020;69:gutjnl2020-321927.

44 Hansen R, Meade S, Beattie RM, et al. Adaptations to the current ECCO/ESPGHAN guidelines on the management of paediatric acute severe colitis in the context of the COVID-19 pandemic: a Rand appropriateness panel. Gut 2020;395:gutjnl-2020-322449.

45 Ungaro RC, Brenner EJ, Gearry RB, et al. Effect of IBD medications on COVID-19 outcomes: results from an international registry. Gut 2021;70:725-32.

46 Lees CW, Irving PM, Beaugerie L. COVID-19 and IBD drugs: should we change anything at the moment? Gut 2021;70:6324.

47 Alexander JL, Moran GW, Gaya DR, et al. SARS-CoV-2 vaccination for patients with inflammatory bowel disease: a British Society of gastroenterology inflammatory bowel disease section and IBD clinical research Group position statement. Lancet Gastroenterol Hepatol 2021;6:218-24.

48 Siegel CA, Melmed GY, McGovern DP, et al. SARS-CoV-2 vaccination for patients with inflammatory bowel diseases: recommendations from an international consensus meeting. Gut 2021;70:635-40. 